\title{
Validation of the Mathematical Modeling Attitude Scale for Malaysian Mathematics Teachers
}

\author{
Riyan Hidayat ${ }^{1 *}$, Wan Izani Wan Idris ${ }^{2}$, Hilman Qudratuddarsi ${ }^{3}$, Muhamad Nazri Abdul Rahman ${ }^{4}$ \\ ${ }^{1}$ Department of Mathematics, Faculty of Science and Mathematics, Universiti Pendidikan Sultan Idris, 35900, Perak, MALAYSIA \\ 2 Bahagian Pengurusan Sekolah Harian, Kementerian Pendidikan Malaysia, MALAYSIA \\ ${ }^{3}$ Department of Mathematics and Science Education, Faculty Education, Universiti Malaya, 50603, Kuala Lumpur, MALAYSIA \\ ${ }^{4}$ Department of Planning, Research and Innovation, Institute of Teachers Education, MALAYSIA
}

Received 11 August 2021 • Accepted 15 November 2021

\begin{abstract}
This work sets out to examine the validity and reliability of the Mathematical Modeling Attitude Scale (MMAS), a instrument measuring teachers' attitude towards mathematical modeling. A cross-sectional survey research was utilised to describe the validity and reliability of the MMAS. The population of the present study focused on Malaysian mathematics teacher in primary and secondary schools $(N=171)$ and this was achieved using convenience sampling. Exploratory factor analysis (EFA), confirmatory factor analysis (CFA) and Rasch analysis were utilised in analysing the data in the present work. EFA revealed that the data from the teachers had a fourfactor structure: constructivism, relevance and real-life, understanding and motivation and interest. The CFA confirmed that the model fit indices established the four-factor structure of the first- and second-order model. Although the Rasch analysis generally supported the finding of EFA and CFA, there was still room for improvement in terms of the rating scale and DIF criterion.
\end{abstract}

Keywords: attitude, exploratory factor analysis, confirmatory factor analysis, mathematical modeling, Rasch analysis

\section{INTRODUCTION}

There has been increased focus on mathematical modelling in recent years (Albarracín, 2021) especially in the Asian context (Hidayat et al., 2018, 2021; Leong \& Tan, 2020). The mathematical modeling approach plays an important role in Mathematics education (Galbraith, 2017; Shahbari \& Peled, 2015) in terms of connecting workplace mathematics and classroom mathematics (Kohen \& Orenstein, 2021). The Common Core State Standards for Mathematics (CCSSM) characterize mathematical modeling as a $\mathrm{K}-12$ standard for practice in mathematics and as a conceptual cluster for secondary education (CCSSI, 2010). Moreover, recent research (Hallström \& Schönborn, 2019) states that model and modeling concepts should be used as tools to promote science, technology, engineering and mathematics (STEM) literacy and the transfer of knowledge and skills between contexts both within and outside STEM disciplines. Surprisingly, policymakers and business leaders rely heavily on mathematical analysis and modelling for direction and decision-making (Hunt, 2007). Mathematical modeling is also deeply engaged in the industrial partnerships, outreach efforts, and any other real-world connections.

Sabudin and Halim (2020) stated that the need for teacher training shapes the knowledge, skills and attitudes of teachers in teaching and learning. Teachers have a critical role in designing and applying these mathematical modelling requirements. The importance for teachers to have a good attitude toward mathematics (Leavy et al., 2017), including mathematical modeling (Asempapa \& Brooks, 2020) has long been recognised. Attitudes toward mathematics are influenced by material coverage, teaching technique, and teaching quality (Ayob \& Yasin, 2017). What and how teachers educate are influenced by their attitudes. Moreover, individuals will be inspired to view mathematics positively if teachers emphasise student-centered instruction, such as assigning tasks based on students'

(c) 2021 by the authors; licensee Modestum. This article is an open access article distributed under the terms and conditions of the Creative Commons Attribution License (http://creativecommons.org/licenses/by/4.0/). 


\section{Contribution to the literature}

- This work sets out to examine the validity and reliability of the Mathematical Modeling Attitude Scale (MMAS) in the Malaysian context.

- The current study is conducted to examine variations in teachers' attitudes towards using mathematical modelling between urban and rural instructors.

- The current investigation focuses on mathematical modeling attitude scale using EFA, CFA and employing Rasch measurement model.

abilities and encouraging team project among classmates when tackling mathematical issues (Hamed et al., 2008). Mathematical modeling approach is seen to be appropriate to enhance attitudes toward mathematics since it involves group activity, the application of realworld situations, a deeper learning experience, and an iterative procedure. A favourable attitude toward mathematics may be created when teaching mathematical applications (Kasmin et al., 2019) and this can be done via gamification (Ali et al., 2019). However, many mathematics and science teachers hold a weak attitude (Tajudin \& Abdullah, 2018) and do not believe modelling is an excellent way to learn mathematics, and many frequently doubt their own mathematical modelling abilities (Albarracín \& Gorgorió, 2020). Hence, it is worthwhile to investigate and establish an instrument of teachers' attitudes regarding mathematical modelling.

However, the use of instrument of teachers' attitudes regarding mathematical modelling is limited. Given the significance of mathematical modelling and its impact on teachers' attitude, it is critical to comprehend how to apply the most suitable valid instrument. We follow the idea of Asempapa and Brooks (2020) to measure teacher attitude mathematical modeling including subdimensions of constructivism, understanding, relevance and real-life and motivation and interest. As many scholars routinely adopt measures from one cultural context to another, numerous scholars provide proof on reliability and validity challenges. In order to implement a mathematical modeling attitude scale in Malaysian settings, a validated, culturally tailored test in Malaysia is required to measure teachers' attitude towards mathematical modeling. Moreover, studies beyond the United States (US) are needed to confirm and test the instrument, as well as its applicability to teachers in other countries. On the basis of tests that were skewed due to cultural background, broad findings of questionable validity were obtained. As stated by Clarke (2013), a range of cultural roots are becoming more apparent.

Most of the previous studies focus on using exploratory factor analysis (EFA) and confirmatory factor analysis (CFA) to examine evidence on validity and reliability problems across cultural background. Since the current research employs Rasch modeling analysis, it will generate new insight to the body of knowledge in terms of validating the teachers' mathematical modeling attitude for the Malaysian settings. Extant literature proves that a comparative study towards mathematical modeling attitude scale is generally an accepted measure for attitude towards mathematical modeling. However, content, internal structure, and correlation among sub-construct of mathematical modeling attitude scale are important factors to consider in EFA and CFA. The current investigation focuses on the mathematical modeling attitude scale using EFA, CFA and employing Rasch measurement model to validate in order to identify deviant response such as person-fit statistics and item-fit statistics (Widhiarso \& Sumintono, 2016), person response and instrument quality (Bond \& Fox, 2015) and also focusing only on item-fit statistics (high interrelation among items). As a result, this work sets out to examine the validity and reliability of mathematical modeling attitude scale (MMAS), an instrument measuring teachers' attitude towards mathematical modeling adopted from Asempapa and Brooks (2020). One potential issue that may occur while adopting mathematical modelling attitude is the disparity between urban and rural areas. As a result, the current study was conducted to examine variations in teachers' attitudes towards using mathematical modelling between urban and rural instructors. The current study would focus on answering the following research questions:

1. Could the mathematical modeling attitude scale be successfully adapted in the Malaysian context?

2. Is the Malaysian version of mathematical modeling attitude scale valid and reliable?

\section{LITERATURE REVIEW}

\section{Mathematical Modeling}

The goal of mathematical modelling is to show students that the mathematics they are learning can be applied to real-world situations. Mathematizing realworld events and developing mathematical models to represent the phenomena investigated are both part of mathematical modelling (Albarracín, 2021). In Mathematics education, mathematical modelling refers to the development of activities in a classroom setting in which learners are active in the search for answers to real-world issues using mathematical understanding 
(Araújo \& Lima, 2020). Mathematical modelling is often concerned with utilising mathematics to analyse, explain, and comprehend things outside of the mathematical realm (Leung, 2019). As it incorporates the feature of practising mathematics, mathematical modelling provides a deeper learning experience for the student (Burkhardt, 2006). However, mathematical modelling procedure is typically seen as a group activity. A diverse group of students develops comprehensive mathematising skills through the modelling cycle. Every learning activity begins with a whole-group conversation to exchange ideas, followed by an individual or small-group exercise, and concluded with a whole-group conversation of the analysis (Cobb \& Gravemeijer, 2008).

The essence of mathematical modelling is problem discovery before problem solving (Pollak, 2011). As a procedure, mathematical modelling employs sharable, changeable, and reusable conceptual tools to describe, predict, and regulate real-world circumstances (Doerr et al., 2014), which are iterative procedures (Asempapa \& Brooks, 2020). Models are interpreted, defined, clarified, justified, ignored, or modified by learners (English, 2003). Mathematical modeling is an external representation of the modeling process (Sahin et al., 2019). In short, modeling competency refers to the modeling process itself (Blum et al., 2007; Maaß, 2006). Blum and Leiß (2007) provided the complex definition of mathematical modeling starting from constructing, simplifying, mathematising, working mathematically, interpreting, validating and exposing. As stated by Maaß (2006), making assumptions, recognising quantities, constructing relationships, and searching for accessible information are all ways to comprehend the real situation and build a model based on reality. To create a mathematical model based on the real model, students need to mathematize, simplify important values, and select acceptable mathematical equations. Next, to address mathematical questions within the framework of this mathematical model, this enables the students to employ heuristic techniques and mathematical understanding. At the same time, they are also allowed to properly comprehend mathematical results, generalise solutions, and evaluate solutions. Finally, for the validation stage, they are required to to critically examine and reflect, to evaluate certain aspects of the model, to consider other approaches, and to generally challenge the model.

\section{Mathematical Modeling Attitude Scale (MMAS)}

Leading researchers have provided many conceptions for attitudes available in the current literature (Aiken, 1970; Di Martino \& Zan, 2001; Hannula, 2002). They are more likely to consider the appropriateness of the definition than its truth: the adequacy of the definition depends on the issues studied (Di Martino, 2016). Although there is no standard concept of the term attitude, it generally refers to a predisposition or tendency to respond to some object, situation, concept, or other person (Aiken, 1970). As stated by Mcleod (1992), attitude refers to affective responses including positive or negative feelings with moderate intensity and reasonable stability. Examples of attitudes towards mathematics include liking geometry, disliking word problems, and being bored with algebra. However, further definitions of attitudes have been established by current investigators. Attitude is also defined as the evaluative process of emotions aroused by the situation, emotions related to the stimulus, expected consequences, and linking the situation with personal values (Hannula, 2002). In addition, to understand the concept of attitude, the latest model suggests three main dimensions: emotional disposition towards mathematics, mathematical views, and perception of competence in mathematics (Di Martino, 2016).

In line with the conception of attitude mentioned above, Di Martino and Zan (2001) distinguish two important typologies for the definition of attitudes. First, the definition of a 'moderate' attitude describes it as a positive or negative level of feeling related to a particular subject. For example, according to this view, attitudes towards mathematical modeling may refer to only positive or negative emotional tendencies towards modeling involving emotions, associations, expectations, and values. Unfortunately, this type of definition ignores the cognitive component in attitude (Hannula, 2002). Second, this concept is closely related to other elements that influence the existence of attitudes. Attitudes according to this typology are defined as three closely interrelated components in attitudes; emotional responses, beliefs about the subject, behavior toward the subject.

However, in order to capture teachers' attitudes about mathematical modelling scale (MMAS), the idea of Asempapa (2018), and Asempapa and Brooks (2020) were employed. Asempapa (2018) defined teachers' attitude towards modeling practices in classroom as a beneficial influence linked to mathematical modeling instructions. At the same time, mathematical modelling can assist in the formation or reinforcement of beliefs about the value and concreteness of mathematics (Di Martino, 2019). Furthermore, mathematical modelling can be used to inspire students to complete curriculum requirements and to emphasise the value and relevance of mathematics in resolving significant topics. In brief, mathematical modeling is one of the ways to offer student making connection mathematics with other fields and to work professionally with mathematical modelling. In the current research we followed the idea of Asempapa and Brooks (2020) involving subdimensions of constructivism, understanding, relevance and real-life and motivation and interest.

Constructivism and understanding refer to cognitive components in the teaching of mathematical modelling. 
Relevance and real-life refer to behavioral components linked to teaching modeling. Finally, motivation and interest refer to affective components linked to teaching modeling. In constructivist education, Singer and Moscovici (2008) developed a learning cycle that incorporates problem posing as an elaboration and implementation of problem solving. According to Asempapa and Brooks (2020), constructivist pedagogy usually believes that children perceive mathematics as a result derived from real-world situations. Constructivist teaching approaches highlight reflective, negotiated, inductive, and cooperative components in instruction (Tiilikainen et al., 2019). At the same time, mathematical modelling usually necessitates the translation of formal mathematical components in terms of (personal or social, non-mathematical) fact as stated by Hennig (2010). It may be stated that mathematical modelling incorporates constructivism's philosophy in mathematics teaching.

Understanding towards mathematical modeling, as a cognitive component, becomes a required component of the Common Core State Standards (CCSS). Ferri (2014) indicated that future instructors must have a solid understanding of many aspects of modelling as well as effective strategies for teaching modelling. Several research indicate also in the same direction in terms to the importance of the teacher's role in the modelling cycle (Barquero et al., 2018; Stillman et al., 2013). To engage in modeling-based activities in the classroom, instructors must possess a broader range of abilities. Teaching mathematical modelling necessitates a respect for mathematical reasoning, a grasp of the modelling process, the ability to link mathematics to real-world problems, and an awareness of how concepts and techniques interact (Asempapa \& Brooks, 2020). In terms of relevance and real-life, Kohen and Orenstein (2021) found the link between workplace mathematics and classroom mathematics as demonstrated via mathematical modelling. At the same time, mathematical modelling is applicable to a variety of fields and is regarded as an excellent tool for STEM education (Hallström \& Schönborn, 2019). Hence, Asempapa and Brooks (2020) measured teachers' inclination towards action of relevance and real-life in modeling classroom. Finally, the attitude object could be a social group, a product or a person (Albarracín et al., 2005). When researching attitudes, it is critical to assess one's perceptions and views regarding an object (Osborne et al., 2003) as generally indicated in terms such as prefer, enjoy, dislike, hate, and love. In mathematical modeling activities, a variety of scenarios can help build not just general educational usefulness, but also mathematical usefulness and mathematical education values (Doruk, 2012). Hence, values and usefulness of mathematical modeling could be measured by teachers' motivation and interest in modeling activities.

\section{METHODOLOGY}

\section{Design and Sample}

A non-experimental quantitative research design was employed in the current research. We utilised a crosssectional survey research to describe the validity and reliability of mathematical modeling attitude for Malaysian mathematics teacher. A cross-sectional study is a study that looks at a group of people at one moment in time (Campbell et al., 2007) to indicate the population's attitudes, views, behavior, or traits (Creswell, 2014). The present study's population are Malaysian mathematics teacher in primary and secondary schools. The approach of convenience sampling (Creswell, 2012) was utilised because of the researcher's proximity and accessibility (Anderson \& Mittal, 2000) to where the participants were given an online survey.

Before finishing the online questionnaires, the research's goal were disclosed, and each participant signed a written consent form. Teachers were asked to complete an anonymous survey that sought demographic information as well as their opinions on mathematical modeling attitude. We gathered biographical responses from participants in the first part, such as gender, school locations, teaching experience, and educational level. In the second part, we wanted to examine the variables relevant to the research question. Finally, this study enlisted the participation of 171 mathematics teachers in Malaysia. There were 87 participants $(51 \%)$ living in urban areas, and the remaining 84 participants $(49 \%)$, were living in rural areas. There were 36 male participants $(21 \%)$ and the remaining were $135(79 \%)$ female teachers. The number of respondents from primary and secondary schools were $69(40 \%)$ and $102(60 \%)$ participants, respectively.

\section{Instruments}

The measures of the mathematical modeling attitude were adopted from a study conducted by Asempapa and Brooks (2020). The mathematical modeling attitude scale consists of 28 questions scored on a 6-point Likert scale ranging from 1 (strongly disagree) to 6 (strongly agree). There are four dimensions to the scale including constructivism (6 items; e.g., 'exploratory skills through mathematical modeling foster conceptual understanding'), relevance and real-life (7 items; e.g., 'mathematical modeling is a worthwhile tool for understanding mathematics"), understanding (5 items; e.g., 'I understand modeling with mathematics'), and motivation and interest (10 items; e.g., 'mathematical modeling motivates students to learn mathematics').

\section{Data Analysis}

Several stages were involved in analyzing data in the present work. The use of EFA, CFA and Rasch analysis 
improved the credibility of research results in a number of different ways. EFA was used in the first step of the empirical method to explore the pattern and interconnections of the items using IBM SPSS Statistics Version 23.0. EFA is employed to investigate correlations between observed variable and to model these correlations using one or more latent variables (Goretzko et al., 2019). The main component of EFA used in this study was varimax rotation and Kaiser criteria, but Osbourne (2015) indicated that it was not optimal. As such, in this study the Kaiser-Meyer-Olkin (KMO) value, Bartlett, factor loading, eigen value, scree plot, and varimax rotation were determined. The Kaiser-MeyerOlkin Measure of Sampling Adequacy and Bartlett's Test of Sphericity were employed to determine if the data was suitable for factor analysis. The $p$ score for the Bartlett test was less than .05 , indicating that the data set was not an identity matrix. KMO has a general acceptability value greater than 0.6. Eigenvalues larger than one indicate the presence of separate components. Next, the scree plot was inspected again to ensure the number of dimensions that should be preserved. For Hair et al. (2010), the overall value of factor loading for each item that exceeds .50 is significant for validating the questionnaire meaningfulness.

CFA has long been used in mathematics education (Asempapa \& Brooks, 2020; Hidayat et al., 2021) and psychological study (Hidayat et al., 2018; Yong et al., 2020) to describe the theoretical aspects of instruments. We used CFA to examine if the original dimension structure remained true in Malaysian contexts employing the IBM SPSS AMOS, version 18. A total of two models were examined. The model parameters for the first- and second-order models for the mathematical modeling attitude scale were conducted. The first-order model was examined based on Asempapa and Brooks (2020) involving four dimensions. Next, we developed a second-order model in which the four mathematical modeling attitude dimensions worked on a higher-order latent variable. To evaluate and compare the overall model fit of the first and second-order models, different goodness-of-fit indicators were employed in this work to assess the adequacy of the postulated models. The following were the requirements for a good fit: chisquare test $(p>0.05)$ (Hooper et al., 2008), $\chi^{2} /$ degrees of freedom $(<.50)$, the comparative fit index (CFI) (>.90), the Tucker-Lewis index (TLI) (>.90) (Wang \& Wang, 2019), the root mean square error of approximation (RMSEA) (<1.0) (Awang, 2012; Hu \& Bentler, 1999).

The research questions were also computed by means of Rasch analysis, employing the WINSTEPS version 3.73. We provided reliability, separation, fit statistics, rating scale, unidimensionality, and item bias in Rasch analysis. There are various fit statistics to evaluate in order to verify model fitness in Rasch analysis: the unidimensionality test, differential item functioning (DIF), item person separation reliability, Rasch model fit of items, threshold order for all items and the assumption of local independence in item. To ensure its construct validity, there are some fit statistics to consider: (a) the value of accepted infit and outfit mean square (MNSQ): $.5<\mathrm{MNSQ}<1,5$ (b) the value of accepted Correlation Points (Pt Mean Corr): .4 < Pt Measure Right $<.85$ (Boone et al., 2014). Rasch analysis allows the transformation of data. Transformation from the raw values to interval values are easier to interpret because across the scale, each change in one unit has similar weight (Alnahdi, 2018).

Finally, Cronbach's alpha coefficients (Cohen et al., 2011), composite reliability (CR) and average variance extracted (AVE) (Zainudin Awang et al., 2018) are used to determine reliability, discriminant validity and convergent validity. Construct reliability (CR) (more than .60) and average variance extracted (AVE) of more than .50 are acceptable (Zainudin Awang et al., 2018). Convergent validity is achieved when an observed variable significantly correlates with latent variables (Obrad, 2020). Discriminant validity refers to whether the constructs truly vary from one another (Ab Hamid, 2017). Average Variance Extracted (AVE) can be used to determine convergent validity. A value that is greater than one .50 is a desirable AVE index. The discriminant validity is additionally calculated by AVE scores which are higher than the maximum shared variance (MSV) and average shared variance (ASV) values (Hair et al., 2014).

\section{RESULT}

\section{Descriptive Analysis}

The sub-dimensions were computed, as revealed in Table 1, for Mean, standard deviation (SD), skewness, kurtosis and inter-correlation.

Based on Table 1, kurtosis and skewness values for all sub-dimensions and items fell within -3 and +3 (Brown \& Greene, 2006) when using SEM. An evaluation of the multivariate normality analysis as indicated by Mardia (1970) that the kurtosis score to be 279.38 with a critical ratio of 44.57 , indicated that the study's collected data was not normally distributed. We employed bootstrapping (500 resamples) for this data set to achieve more precise and reliable estimations (Awang, 2012). All scale items had significant relationships, and the four sub-dimensions had modest to strong associations (ranging from $r=.46$ to $r=.81, p<=.01$ ). All associations were less than .90 , indicating that there was no multicollinearity (Kline, 2005). The mean score differed each sub-dimensions, with $\mathrm{M}=4.71$ and $\mathrm{SD}=.75$ for constructivism, $\mathrm{M}=4.61$ and $\mathrm{SD}=.73$ for relevance and real-life, $\mathrm{M}=4.17$ and $\mathrm{SD}=.77$ for understanding and $\mathrm{M}$ $=4.42$ and $\mathrm{SD}=.78$ for motivation and interest. 
Table 1. Sub-dimensions with their mean values, SD, skewness, and kurtosis

\begin{tabular}{|c|c|c|c|c|c|c|c|c|}
\hline Sub-dimensions & Mean & SD & Skew & Kurtosis & 1 & 2 & 3 & 4 \\
\hline Constructivism & 4.71 & .75 & -.77 & 2.81 & 1 & $.53^{* *}$ & $.27^{* *}$ & $.53^{* *}$ \\
\hline Relevance and real-life & 4.61 & .73 & .05 & -.41 & & 1 & $.58^{* *}$ & $.81^{* *}$ \\
\hline Understanding & 4.17 & .77 & -.20 & -.13 & & & 1 & $.46^{* *}$ \\
\hline Motivation and interest & 4.42 & .78 & -.09 & -.05 & & & & 1 \\
\hline
\end{tabular}

**. Correlation is significant at the 0.01 level (2-tailed).

Table 2. The results of the EFA

\begin{tabular}{|c|c|c|c|c|c|c|c|c|}
\hline \multirow{2}{*}{ Sub-Dimensions } & \multirow{2}{*}{ Items } & \multirow{2}{*}{ Communalities } & \multirow{2}{*}{ Eigenvalue } & \multirow{2}{*}{$\%$ of Variance } & \multicolumn{4}{|c|}{ Loading Factor } \\
\hline & & & & & 1 & 2 & 3 & 4 \\
\hline \multirow{6}{*}{ Constructivism } & B1 & .73 & 2.40 & 8.58 & & & .83 & \\
\hline & B2 & .81 & & & & & .86 & \\
\hline & B3 & .79 & & & & & .86 & \\
\hline & B4 & .65 & & & & & .73 & \\
\hline & B5 & .74 & & & & & .77 & \\
\hline & B6 & .77 & & & & & .76 & \\
\hline \multirow[t]{7}{*}{ Understanding } & D1 & .85 & 3.06 & 10.93 & & .75 & & \\
\hline & D6 & .76 & & & & .64 & & \\
\hline & D2 & .84 & & & & .72 & & \\
\hline & D3 & .85 & & & & .72 & & \\
\hline & D4 & .82 & & & & .66 & & \\
\hline & D5 & .81 & & & & .67 & & \\
\hline & D7 & .77 & & & & .68 & & \\
\hline \multirow{5}{*}{$\begin{array}{l}\text { Relevance and real- } \\
\text { life }\end{array}$} & $\mathrm{C} 1$ & .79 & 1.24 & 4.42 & & & & .85 \\
\hline & $\mathrm{C} 4$ & .56 & & & & & & .61 \\
\hline & $\mathrm{C} 2$ & .85 & & & & & & .89 \\
\hline & C3 & .80 & & & & & & .80 \\
\hline & C5 & .82 & & & & & & .87 \\
\hline \multirow{10}{*}{$\begin{array}{l}\text { Motivation and } \\
\text { interest }\end{array}$} & E1 & .79 & 15.42 & 55.09 & .80 & & & \\
\hline & E2 & .77 & & & .80 & & & \\
\hline & E3 & .77 & & & .70 & & & \\
\hline & $\mathrm{E} 4$ & .76 & & & .73 & & & \\
\hline & E5 & .88 & & & .87 & & & \\
\hline & E6 & .87 & & & .82 & & & \\
\hline & E7 & .82 & & & .79 & & & \\
\hline & E8 & .84 & & & .82 & & & \\
\hline & E9 & .83 & & & .84 & & & \\
\hline & E10 & .77 & & & .81 & & & \\
\hline
\end{tabular}

\section{Exploratory Factor Analysis}

The outputs of the EFA recommended that four factors explained $79 \%$ of the variance (Table 2). The Kaiser-Meyer-Olkin Measure of Sampling Adequacy was .94, indicating that the sample was appropriate, and Bartlett's Test of Sphericity provided a $p$-value of $<0.001$. According to Osbourne (2015), these values were not enough. Therefore, the current research employed KMO, Bartlett, factor loading, eigen value, scree plot, and varimax rotation.

Based on Table 2, the communalities for these 28 questions ranged from .56 to .88 . The first factor (which explained $55.09 \%$ of the variance) corresponded to the factor of motivation and interest; the second factor (which explained $10.93 \%$ of the variance) corresponded to the factor of understanding; the third factor (which explained $8.58 \%$ of the variance) corresponded to the factor of constructivism; and the last factor (which explained $4.42 \%$ of the variance) corresponded to the factor of relevance and real-life. The highest loading factor was item C2 (.89) (factor of relevance and real-life) while the lowest loading factor was item C4 (.61) (factor of relevance and real-life). The highest loading factor was item E5 (.86) (factor of motivation and interest) while the lowest loading factor was item E3 (.70) (factor of motivation and interest). The highest loading factor was item D1 (.75) (factor of understanding) while the lowest loading factor was item D6 (.64) (factor of understanding). The highest loading factor was item B3 (.86) (factor of constructivism) while the lowest loading factor was item B4 (.73) (factor of constructivism). However, the factor loadings on all of the items were more than .50. There were no cross-loadings in the present work. The scree-plot test backed up the choice to keep four factors; hence the research maintained four factors (Figure 1). 


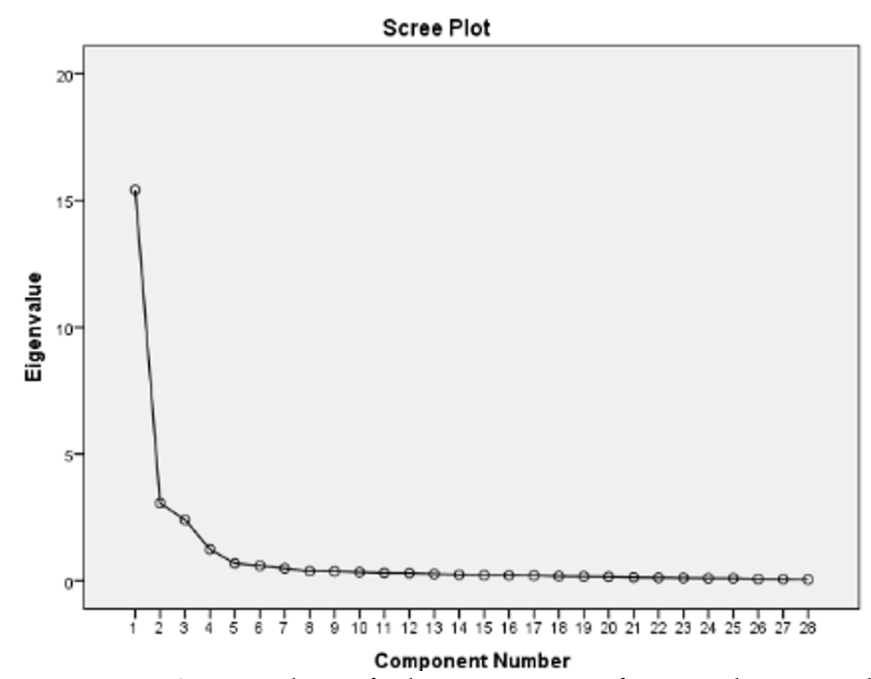

Figure 1. Scree plot of the 28 items for mathematical modeling attitude

\section{Confirmatory Factor Analysis}

As the EFA recommended a four-factor solution, confirmatory factor analysis was carried out in the present work. AMOS software was used to analyse and compare the overall fit of the two frameworks: a firstorder model consisting of four mathematical modeling attitude components and a second-order model, called the mathematical modeling attitude scale. In terms of a first-order model, the goodness of model-data fit were $\left(\chi^{2}(171)=864.008, p=.00, \chi^{2} / \mathrm{df}=2.512, \mathrm{CFI}=.904, \mathrm{TLI}\right.$ $=.900$, and RMSEA $=.094$, revealing an acceptable and a moderate model-data fit. The item factorial loads for a first-order model varied from .757 to .942. All of the factor loadings were more than .50 and considered acceptable (Hair et al., 2010). Furthermore, the correlations between the mathematical modeling attitude factors varied from .285 to .828 ; covariances were also statistically significant (critical ratios ranged from 3.238 to 7.331 ), indicating that the mathematical modeling attitude factors were not independent. As a result, the CFA model depicted in Figure 2 is the final first-order model that depicts the structure of a mathematical modeling attitude scale in the Malaysian context.

At the same time, in terms of a second-order model, the goodness of model-data fit were $\left(\chi^{2}(171)=868.834, p\right.$ $=.00, \chi^{2} / \mathrm{df}=2.511, \mathrm{CFI}=.904, \mathrm{TLI}=.900$, and RMSEA $=.094$, indicating an acceptable and a moderate modeldata fit. The item factorial loads for a second-order model varied from .756 to .943 . All of the factor loadings were more than .50 and considered acceptable (Hair et al., 2010). The path coefficients for mathematical modeling attitude factors varied among sub-factors: constructivism (.58), relevance and real-life (.98),

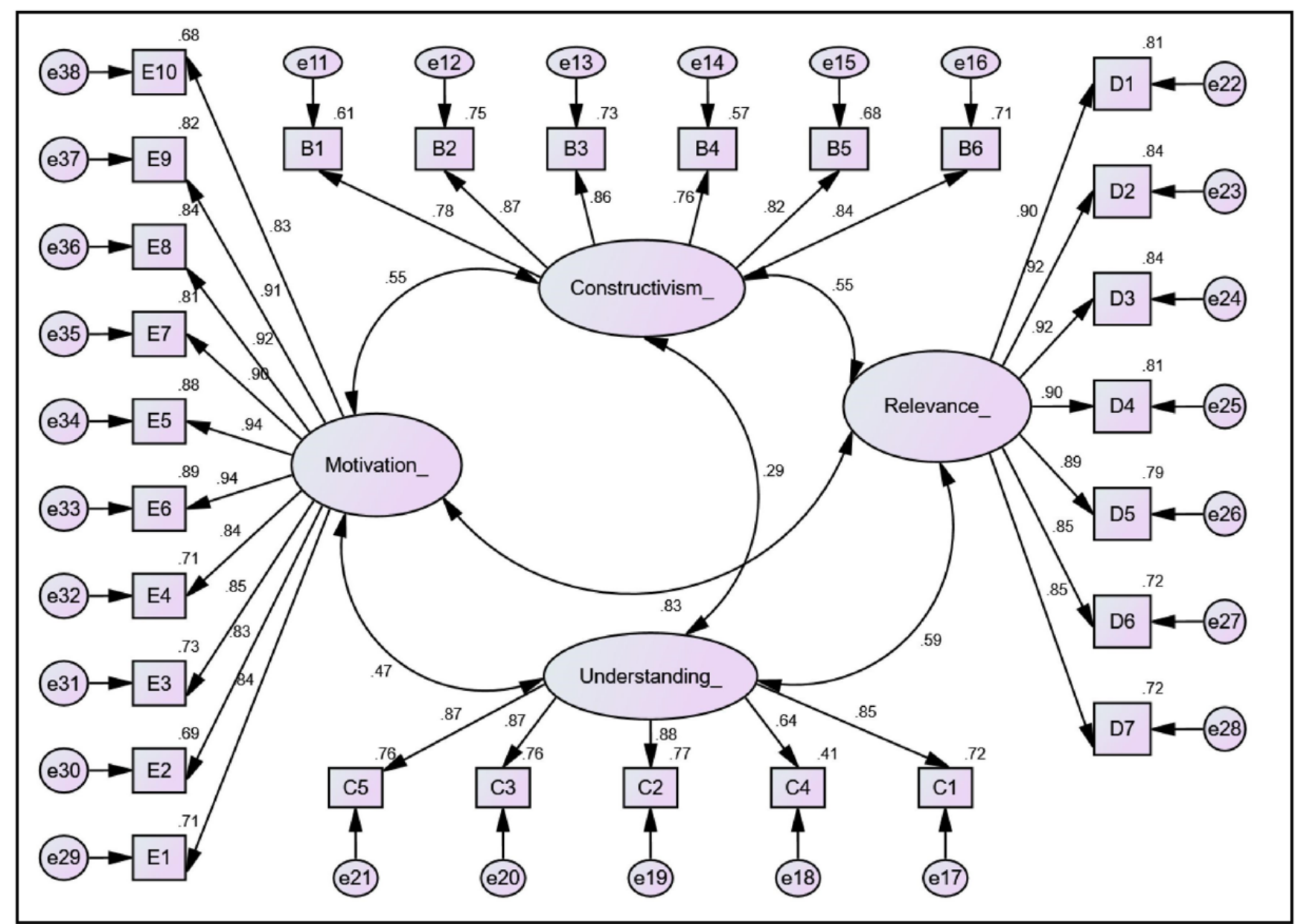

Figure 2. The final first-order model for mathematical modeling attitude 


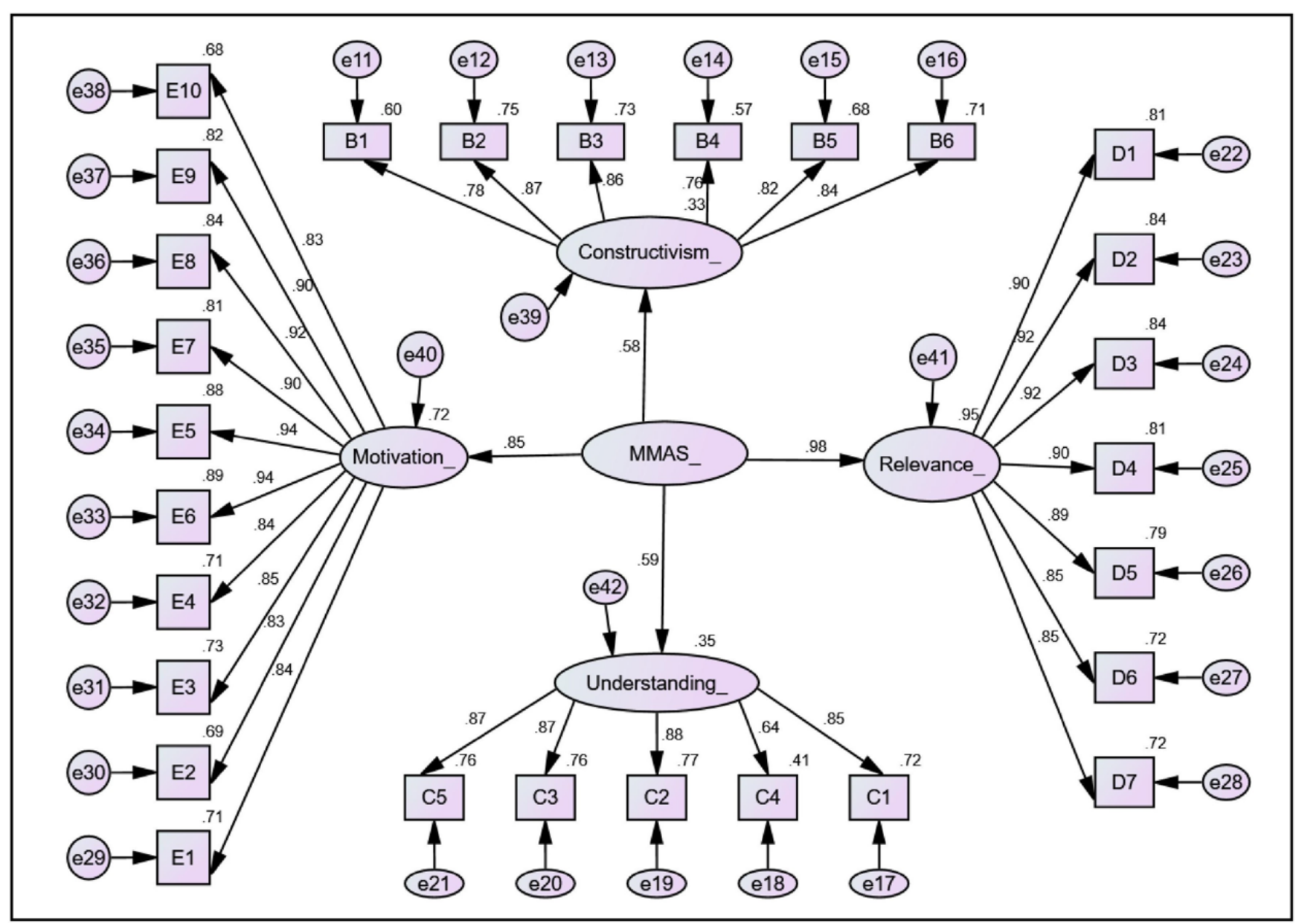

Figure 3. The final second-order model for mathematical modeling attitude

Table 3. The first- and second-order model comparison

\begin{tabular}{llcc}
\hline \multirow{2}{*}{$\begin{array}{l}\text { Goodness-of- } \\
\text { fit }\end{array}$} & Criterion & \multicolumn{2}{c}{ Model } \\
\cline { 3 - 4 } & & $\begin{array}{c}\text { First-order } \\
\text { model }\end{array}$ & $\begin{array}{c}\text { Second-order } \\
\text { model }\end{array}$ \\
\hline$\chi^{2}$ & $p>0.05$ & 864.008 & 868.834 \\
$\chi^{2} / d f$ & $<5.00$ & 2.512 & 2.511 \\
CFI & $>0.900$ & .904 & .904 \\
TLI & $>0.900$ & .900 & .900 \\
RMSEA & $<1.00$ & .094 & .094 \\
\hline
\end{tabular}

understanding (.59) and motivation and interest (.85). As a result, the CFA model depicted in Figure 3 is the final second-order model that depicts the structure of a mathematical modeling attitude scale in the Malaysian context.

The model parameters for the first- and second-order models for the mathematical modeling attitude scale are shown in Table 3. When the two models were compared, it was clear that the final first-order model for the mathematical modeling attitude scale fit better than the second-order one. In other words, the goodness-of-fit indices for the second-order model of the mathematical modeling attitude scale were less favorable. However, both model parameters met the criteria for excellent model-data fit.

\section{Reliability of the Mathematical Modeling Attitude Scale}

We examined the reliability of the mathematical modeling attitude sub-scales (constructivism, relevance and real-life, understanding, and motivation and interest) and overall mathematical modeling attitude items for the total respondents $(\mathrm{N}=171)$ (see Table 4). In the present work, internal consistency scores were: a) constructivism: $\alpha=.92, b$ ) relevance and real-life: $\alpha=.96$, c) understanding: $\alpha=.91$, and $\mathrm{d}$ ) motivation and interest: $\alpha=.97$. The scale's mathematical modeling attitude were excellent Cronbach alpha coefficient (Hair et al., 2015). The AVE values varied from .67 to .79 , all over 0.5 , demonstrating that each dimension had satisfactory internal consistency (Hair et al., 2017) and supporting convergent validity (Fornell \& Larcker, 1981). Again, MSV and ASV scores were smaller than AVE scores, indicating the good discriminant validity of the mathematical modeling attitude. Finally, composite reliability for the mathematical modeling attitude ranged from .91 to .97 , showing high internal consistency as well. 
Table 4. The measurement model's discriminant validity

\begin{tabular}{llcccccc}
\hline Dimension & Sub-dimensions & $\begin{array}{c}\text { Overall } \\
\text { Cronbach's Alpha }\end{array}$ & $\begin{array}{c}\text { Alpha } \\
\text { Value }\end{array}$ & CR & AVE & MSV & ASV \\
\hline Mathematical & Constructivism & .97 & .92 & .93 & .67 & .30 & .48 \\
modeling attitude & Relevance and real-life & & .96 & .96 & .79 & .69 & .45 \\
& Understanding & & .91 & .91 & .68 & .35 & .22 \\
& Motivation and interest & & .97 & .97 & .78 & .69 & .40 \\
\hline
\end{tabular}

Table 5. Reliability and separation

\begin{tabular}{lcc}
\hline & Person & Item \\
\hline Separation & 3.81 & 4.67 \\
Reliability & .96 & .94 \\
Cronbach's alpha & .97 & \\
\hline
\end{tabular}

\section{Rasch Analysis}

\section{Reliability and separation of instrument}

There are three kinds of reported reliability used when validating instrument based on the Rasch measurement model (Adams et al., 2021). It is mathematical model that pivots on the linear relationship between an item and a person based on latent traits such as perceptions or attitude (Scoulas et al., 2021). The reliability of the mathematical modelling attitude scale in the Malaysian context based on reported analysis using Winstep software version 3.7.3 for person reliability, item reliability and Cronbach's alpha were $.96, .94$ and .97 respectively (Table 5). Another result to consider is that separation of either item or person which should be more than 1.5 to be considered acceptable (Suryadi et al., 2021; Tennant \& Conaghan, 2007). Separation for item and person for the mathematical modelling attitude scale in the Malaysian context were 4.67 and 3.81 respectively. The excellent results of reliability and separation showed that the instrument can separate item and person to some groups very well and show high internal consistencies of the instrument (Iseppi et al., 2021).

\section{Item fit statistics}

The evaluation of item fit statistics is the evidence of construct validity namely mean square (MNSQ) and Correlation Points (Pt Mean Corr). The former fit statistics showed the size of the discrepancies (i.e., randomness) and the latter examined the partial correlation of each item with the total measure score, item reliability, and separation statistics (Alkhadim et al., 2021). The accepted score is .5-1.5 for MNSQ and 0.40.85 for Pt Measure Right (Boone et al., 2014). Most of items had infit and outfit fall beyond the acceptable range except item C1, C3, U1, U2, U5 (infit mean square) and C1, C3, C4, U1, U1, U3, U5 (outfit mean square). The high infit MNSQ score indicated underfitting, showing the responses were too unpredictable from the Rasch model's perspective. The high outfit MNSQ reflected the lucky guesses (i.e., correct response to hard items) or
Table 6. Unidimensionality test result

\begin{tabular}{lcc}
\hline Variance in Eigenvalue units & Eig & Obs (\%) \\
\hline Raw variance explained by measures & 33.8 & $54.7 \%$ \\
Raw Variance explained by persons & 23.1 & $37.4 \%$ \\
Raw Variance explained by items & 10.7 & $17.3 \%$ \\
\hline
\end{tabular}

careless mistakes (i.e., incorrect response to easy items). To fulfil the misfit detection, it is reported that the mathematical modelling attitude scale in the Malaysian context measures correlation ranging from .51-.83, indicating the alignment between students' attitudes and responses to the item (Alkhadim et al., 2021).

\section{Unidimensionality}

Unidimensionality is a measure to explicate the capability of the instrument to estimate what the researchers intend to study. Its score exhibits relationship among items in the instrument. From this analysis, we consider the minimum raw variance explained should be more than 24\% (Purnami et al., 2021). The result of the unidimensionality test of the mathematical modelling attitude scale in Malaysian context can be seen in Table 6. From the table, the instrument exceeded the minimum raw variance explained, accounting for $54.7 \%$ where $37.4 \%$ was obtained from the person and $17.3 \%$ was obtained from the items. There was no need to check the second domain because unexplained variance in the first contrast was lower than $15 \%$, accounting for $9.6 \%$ (He et al., 2021).

\section{Rating scale}

Rasch analysis can calibrate the scale to guarantee that the quoted data is appropriate for processing and analysis (A Aziz et al., 2019). This mathematical modelling instrument has 6 scales comprising "strongly disagree", "disagree", "somewhat disagree", "somewhat agree", "agree", and "strongly agree" (Asempapa \& Brooks, 2020). These categories are analyzed to ensure that the respondents understand well and be able to distinguish each category (Adams et al., 2021). The desirable Rasch-Andrich threshold is 1.40-5.0 logit (Van Zile-tamsen, 2019), but it was found that the distance between "somewhat disagree" and "disagree" was less than the acceptable distance. It was also clear, in Figure 4, that the "disagree" scale did not appear as another scale. 


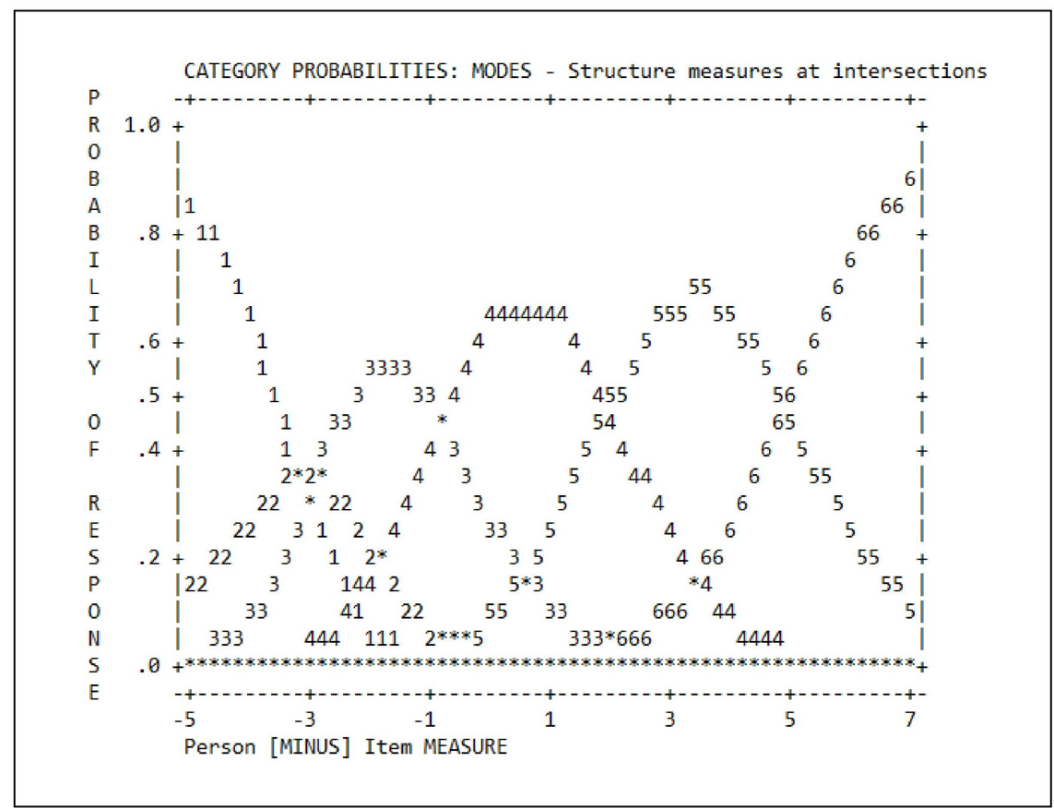

Figure 4. Rating scale calibration

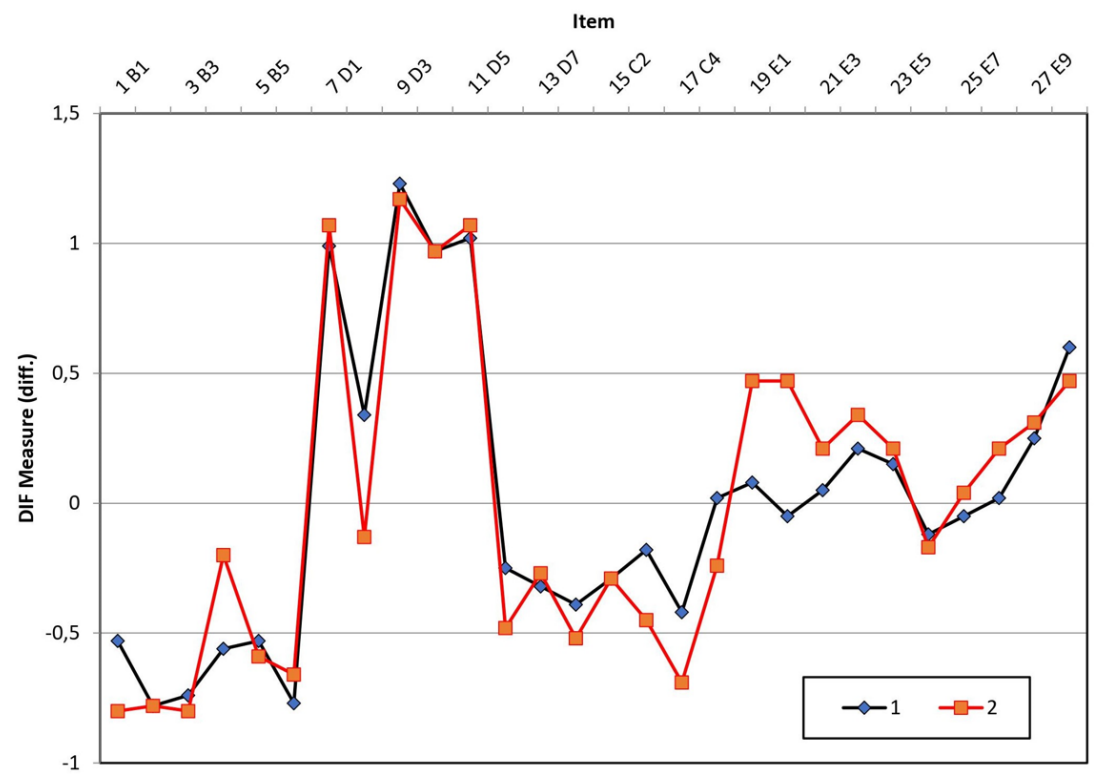

Figure 5. DIF based on school location

\section{DIF based on location}

One vital analysis of the Rasch measurement model is Differential Item Functioning (DIF), a term to detect item bias based on demographic information (Rouquette et al., 2019) (Figure 5). In the current study, an item can be categorized as bias when its probability score on the Chi-Square test based on the Rasch model is less than 0.05 and its DIF contrast lower than .55 (He et al., 2021). Based on the school location, it was found that only one item had a value of $p=.045$, i.e., item E2 (sub-construct of motivation).

\section{DISCUSSION}

This work had set out to examine the validity and reliability of MMAS, a instrument measuring teachers' attitude towards mathematical modeling, adopted from Asempapa and Brooks (2020). The EFA, CFA and Rasch model were employed in this work to analyse and validate the MMAS. The integration of Rasch modelling, EFA and CFA provide a balanced connection in the evaluation of an instrument (Edelen \& Reeve, 2007). The results of this study revealed that the items in the MMAS questionnaire were generally acceptable and transferable for measuring teachers' attitude in mathematical modeling as perceived by Malaysian respondents. The MMAS adequately captured the major four dimensions of mathematical modeling attitude in an internally consistent manner. Consistent with our initial hypothesis, we discovered that the MMAS had a satisfactory EFA and CFA characteristic in general. According to EFA outputs, the data from the teachers 
had a four-factor structure: constructivism, relevance and real-life, understanding and motivation and interest. The study's results were consistent with previous work conducted by Asempapa and Brooks (2020) indicating that the MMAS were quite excellent for the 4-dimension model. The significant correlations discovered between the MMAS dimensions indicated the domains' interdependence and demonstrated that a multidimensional model was a good match for investigating these diverse domains. Our work added to the body of knowledge by demonstrating the repeatability of the MMAS in a diverse cultural environment.

The CFA findings confirmed the EFA conclusion, since the MMAS matched the data quite well. The findings of CFA revealed that the model fit indices established the four-factor structure of the first- and second-order model. At the same time, the MMAS subdimensions also had an excellent convergent and discriminant validity. Constructivism was positively associated to relevance and real-life; and motivation and interest, with high relationship. Again, constructivism was positively linked to understanding with weak correlation. Relevance and real-life were positively associated to understanding and motivation and interest, with high relationship. Finally, understanding was positively related to motivation and interest, with high relationship. We also discovered that all subdimensions had acceptable internal consistency (.92 to .97), person reliability (.96), item reliability (.94) and Cronbach's alpha (.97), which corresponded to Cronbach's alpha in the US version. Hence, we may infer that the four-dimensional structure and the diverse dimensions of constructivism, relevance and real-life, understanding and motivation and interest as characterised by the MMAS emerged applicable to the Malaysian teacher population. The implementation of the EFA and CFA to the MMAS contributed to the confirmation of the correctness and usefulness of the MMAS questionnaire. The Malaysian version of the MMAS may be used to assess teachers in mathematical modeling attitude in Malaysia.

The Rasch analysis provided additional support for these results by examining the quality of each item and answer category on the MMAS questionnaire. The findings of the Rasch analysis revealed that the MMAS had satisfactory item and person reliability. Again, according to the Rasch evaluation, all of the MMAS items had appropriate infit and outfit MNSQ statistics, indicating the alignment between student's attitudes and responses to the item. Although Rasch analysis generally supported the finding of EFA and CFA, there was still room for improvement. The Rasch analysis revealed that the successive answer categories for all sub-domains in the Malaysian version of the MMAS were not situated in the predicted direction. These findings differ from those of the US version of the
MMAS (Asempapa \& Brooks, 2020). The gap between "somewhat disagree" and "disagree" was discovered to be less than the acceptable distance. It was also obvious that the disagree scale did not show as another scale. Therefore, it was possible to modify the rating scale to be 5 scale which could still provide good psychometric properties (Lee \& Paek, 2014; Leung, 2011; Lozano et al., 2008) for the Malaysian version of the MMAS. One partial reason was that respondents were given the option of answering the middle alternative on a 5-point scale. At the same time, the DIF criterion were analysed to detect item bias based on location (rural and urban area). The results showed that one item such as E2 (mathematical modeling enhances classroom discourse in learning mathematics) did not meet the DIF criterion of being in the range of 0.5 . This finding supported previous investigation in STEM competency in Malaysia (Khairani, 2017). This was because teachers in rural schools were similarly deficient in terms of talent, experience, and professional development.

\section{CONCLUSION}

Teachers play an important role in developing and implementing these mathematical modelling objectives. Many mathematics instructors, on the other hand, do not feel modelling is a great method to learn mathematics, and many regularly doubt their own mathematical modelling talents. As a result, it is beneficial to research and develop a tool for teachers' attitudes towards mathematical modelling including understanding, constructivism, relevance and real-life, and motivation and interest. A validated, culturally adapted test in Malaysia was necessary to assess teachers' attitudes towards mathematical modelling in order to deploy the attitude scale in Malaysian contexts. The results of this study revealed that the items in the MMAS questionnaire were generally acceptable and transferable for measuring teachers' attitude in mathematical modeling. EFA outputs revealed that the data from the teachers had a four-factor structure: constructivism, relevance and real-life, understanding and motivation and interest. The findings of CFA revealed that the model fit indices established the fourfactor structure of the first- and second-order model. Although the Rasch analysis generally supported the finding of EFA and CFA there was still room for improvement. For example, in terms of the rating scale and DIF criterion, the current work contributed to the body of knowledge by providing valid instrument for evaluating teachers' attitudes toward mathematical modeling, which was then analysed using EFA, CFA and a strong Rasch model. Lastly, future studies might look at cultural variables influencing survey design and implementation. This implies that the tool may be utilised extensively independent of the grouping factors. 


\section{LIMITATIONS AND FUTURE DIRECTIONS}

Although the MMAS might be used widely in the Malaysian context and the instrument has the potential to be utilised for study and practise in this specific setting, we admit that this study has several drawbacks. First, the most evident limitation was the tiny data set, which reduced the validity of the inferences derived from the data. The data analysis used in this study was based on a sample of data gathered only in two states in Malaysia with limited number of respondents $(\mathrm{N}=171)$, which had an impact on generalisation to other groups in Malaysia. In future research, the repetition of the current findings using bigger random samples from other cultural background can provide more support for the findings' generalizability. Again, future research should focus on both pre-service and experienced instructors. Second, convenience sampling (nonprobability sampling) was utilised in this research and this was dependent on proximity and accessibility of participants due to the Covid situation. This method may not yield a true picture of the people in the research regions. Data was collected via an online tool, which may have excluded those who did not have internet access. Future studies should attempt to obtain data from many sources. Third, female instructors outnumbered male teachers in this research. It is possible to study gender bias in this instrument since the current research found the possibility for diversity in respondents' responses based on location (rural and urban area). Future studies should continue to look for evidence of different backgrounds. Before reaching any definite conclusions, it appears that this study should be replicated with an equal number of males and females. Lastly, future studies might benefit from including such data as a dependant variable to be determined by the instructors' mathematical modelling ability.

Author contributions: All authors have sufficiently contributed to the study, and agreed with the results and conclusions.

Funding: No funding source is reported for this study.

Declaration of interest: No conflict of interest is declared by authors.

\section{REFERENCES}

A Aziz, N. F., Ahmad, H., \& Mat Nashir, I. (2019). Validation of technical and vocational teachers' competency evaluation instrument using the rasch model. Jurnal Pendidikan Sains Dan Matematik Malaysia, 9(1), 18-25. https://doi.org/10.37134/ jpsmm.vol9.1.3.2019

Ab Hamid, M. R., Sami, W., \& Sidek, M. M. (2017). Discriminant validity assessment: Use of Fornell \& Larcker criterion versus HTMT criterion. Journal of Physics: Conference Series, 890(1), 012163. https:/ / doi.org/10.1088/1742-6596/890/1/012163
Adams, D., Chuah, K. M., Sumintono, B., \& Mohamed, A. (2021). Students' readiness for e-learning during the COVID-19 pandemic in a South-East Asian university: A Rasch analysis pandemic. Asian Education and Development Studies. https:/ / doi.org/10.1108/ AEDS-05-2020-0100

Aiken Jr, L. R. (1970). Attitudes toward mathematics. Review of Educational Research, 40(4), 551-596. https://doi.org/10.3102/00346543040004551

Albarracín, D., Johnson, B. T., \& Zanna, M. P. (Eds.). (2005). The handbook of attitudes (pp. 223-271). Lawrence Erlbaum.

Albarracín, L. (2021). Large number estimation as a vehicle to promote mathematical modeling. Early Childhood Education Journal, 49(4), 681-691. https:/ / doi.org/10.1007/s10643-020-01104-x

Albarracín, L., \& Gorgorió, N. (2020). Mathematical modeling projects oriented towards social impact as generators of learning opportunities: A case study. Mathematics, 8(11), 2034. https:// doi.org/10.3390/math8112034

Ali, A. R., Endut, A., \& Embong, R. (2019). Attitude of undergraduate students towards gamification: A case study of Northwest Geo-Political Zone, Nigeria. Journal of ICT in Education, 5, 9-13. https:/ / doi.org/10.37134/jictie.vol5.2.2018

Alkhadim, G. S., Cimetta, A. D., Marx, R. W., Cutshaw, C. A., \& Yaden, D. B. (2021). Studies in educational evaluation validating the research-based early math assessment (REMA) among rural children in Southwest United States. Studies in Educational Evaluation, 68(2020), 100944. https://doi.org/ 10.1016/j.stueduc.2020.100944

Alnahdi, A. H. (2018). Rasch validation of the Arabic version of the lower extremity functional scale. Disability and Rehabilitation, 40, 353-359. https:/ / doi.org/10.1080/09638288.2016.1254285

Anderson, E. W., \& Mittal, V. (2000). Strengthening the satisfaction-profit chain. Journal of Service Research, 3(2), 107-120. https://doi.org/10.1177/ 109467050032001

Araújo, J. D. L., \& Lima, F. H. D. (2020). The mathematization process as object-oriented actions of a modelling activity system. Bolema: Boletim de Educação Matemática, 34(68), 847-868. https:// doi.org/10.1590/1980-4415v34n68a01

Asempapa, R. S. (2018). Development and initial psychometric properties of the mathematical modeling attitude scale. School Science and Mathematics, 119(1), 14-23. https:/ / doi.org/10.1111 /ssm.12311

Asempapa, R. S., \& Brooks, G. P. (2020). Factor analysis and psychometric evaluation of the mathematical modeling attitude scale for teachers of mathematics. Journal of Mathematics Teacher 
Education. https://doi.org/10.1007/s10857-02009482-0

Awang, Z. (2012). Structural equation modeling using AMOS graphic. UiTM Press.

Ayob, A., \& Yasin, R. M. (2017). Factors affecting attitudes towards mathematics. International Journal of Academic Research in Business and Social Sciences, 7(11), 1100-1109. https:/ / doi.org/10.6007/IJARBSS /v7-i11/3548

Barquero, B., Bosch, M., \& Romo, A. (2018). Mathematical modelling in teacher education: Dealing with institutional constraints. ZDM, 50(1), 31-43. https:/ / doi.org/10.1007/s11858-017-0907-z

Blum, W., \& Leiss, D. (2007). How do students' and teachers deal with modelling problems? In C. Haines, P. Galbraith, W. Blum, \& S. Khan (Eds.), Mathematical modelling: Education, engineering and economics, ICTMA (vol. 12, pp. 222-231). Horwood Publishing.

https:/ / doi.org/10.1533/9780857099419.5.221

Blum, W., Galbraith, P. L., Henn, H. W., \& Niss, M. (2007). Modelling and applications in mathematics education: The 14 ICMI study (Vol. 10). Springer Science+Business Media. https:/ / doi.org/10.1007/ 978-0-387-29822-1

Brown, S. C., \& Greene, J. A. (2006). The wisdom development scale: Translating the conceptual to the concrete. Journal of College Student Development, 47(1), 1-19. https:/ / doi.org/10.1353/csd.2006.0002

Burkhardt, H. (2006). Modelling in mathematics classrooms: Reflections on past developments and the future. Zentralblatt Fur Didaktik Der Matematik (ZDM): The International Journal on Mathematics Education, 38(2), 178-195. https://doi.org/10.1007/ BF02655888

Campbell, M. J., Machin, D., \& Walters, S. J. (2007). Medical statistics: a textbook for the health sciences (4th ed.). Wiley.

Clarke, D. J. (2013). Contingent conceptions of accomplished practice: The cultural specificity of discourse in and about the mathematics classroom. ZDM Mathematics Education, 45, 21-33. https:/ / doi.org/10.1007/s11858-012-0452-8

Cobb, P., \& Gravemeijer, K. (2008). Experimenting to support and understand learning processes. In A. E. Kelly, R. A. Lesh, \& J. Y. Baek (Eds.), Handbook of design research methods in education: Innovations in science, technology, engineering, and mathematics learning and teaching (pp. 68-95). Routledge

Common Core State Standards Initiative (CCSSI). (2010). Common Core State Standards for Mathematics. National Governors Association Center for Best Practices and the Council of Chief State School Officers. http://www.corestandards.org/wpcontent/uploads/Math_Standards.pdf
Creswell, J. W. (2012). Educational research: Planning, conducting, and evaluating quantitative and qualitative research. Educational Research (vol. 4). Pearson.

Creswell, J. W. (2014). Research design: qualitative, quantitative, and mixed methods approaches. SAGE Publications, Inc.

Di Martino, P. (2016). Attitudes, beliefs, motivation, and identity in mathematics education. In Attitudes, beliefs, motivation and identity in mathematics education (pp. 2-6). Springer.

Di Martino, P. (2019). The complex relationship between mathematical modeling and attitude towards mathematics. In S. A. Chamberlin, B. \& Sriraman (Eds), Affect in mathematical modeling (pp. 219-234). Springer. https://doi.org/10.1007/978-3-03004432-9_14

Di Martino, P., \& Zan, R. (2001). Attitude toward mathematics: some theoretical issues. In M. van den Heuvel-Panhuizen (Ed.), Proceedings of the 25th conference of the international group for the psychology of mathematics education (vol. 3, pp. 351-358). PME.

Doerr, H. M., Ärlebäck, J. B., \& Costello Staniec, A. (2014). Design and effectiveness of modeling-based mathematics in a summer bridge program. Journal of Engineering Education, 103(1), 92-114. https:/ / doi.org/10.1002/jee.20037

Doruk, B. K. (2012). Mathematical modeling activities as a useful tool for values education. Educational Sciences: Theory and Practice, 12(2), 1667-1672.

English, L. (2003). Mathematical modeling with young learners. In S. J. Lamon, W. A. Parker, \& S. K. Houston (Eds.), Mathematical modelling: A way of life. ICTMA11 (pp. 3-7). Horwood.

Ferri, R. B. (2014). Mathematical modeling - the teacher's responsibility. In Proceedings from the teachers college mathematical modeling Oktoberfest. Teachers College, Columbia University

Fornell C, Larcker DF. (1981). Evaluating structural equation models with unobservable variables and measurement error. Journal of Marketing Research, 19, 39-50. https://doi.org/10.1177/0022243781018 00104

Galbraith, P. (2017). Forty years on: Mathematical modelling in and for education. In A. Downton, S. Livy, \& J. Hall (Eds.), 40 years on: We are still learning! Proceedings of the 40th annual conference of the mathematics education research group of Australasia (pp. 47-50). MERGA.

Goretzko, D., Pham, T. T. H., \& Bühner, M. (2019). Exploratory factor analysis: Current use, methodological developments and recommendations for good practice. Current Psychology, 40, 3510-3521. https:// doi.org/10.1007 / s12144-019-00300-2 
Hair, J. F. Jr., Sarstedt, M., Ringle, C. M., \& Gudergan, S. P. (2017). Advanced issues in partial least squares structural equation modeling. Sage publications.

Hair, J. F., Black, W. C., Babin, B. J., \& Anderson, R. E. (2010). Multivariate data analysis (7th ed.). Pearson.

Hair, J. F., Celsi, M., Money, A., Samouel, P., \& Page, M. (2015). The essentials of business research method (3rd ed.). $2016 \quad$ Faculty Bookshelf. 2. https:/ / doi.org/10.4324/9781315704562

Hair, J. F., Hult, G. T. M., Ringle, C. M., \& Sarstedt, M. M. (2014). A Premier on partial least squares structural equation modeling (PLS-SEM). SAGE Publications.

Hallström, J., \& Schönborn, K. J. (2019). Models and modelling for authentic STEM education: Reinforcing the argument. International Journal of STEM Education, 6(2), 1-10. https://doi.org/ 10.1186/s40594-019-0178-Z

Hamed, S., Bahari, P., \& Abdullah, A. G. K. (2008). Korelasi antara persekitaran pembelajaran matematik, sikap pelajar terhadap matematik, dan pencapaian pelajar dalam matematik: Satu kajian kes [Correlation between mathematics learning environment, students 'attitudes toward mathematics, and student achievement in mathematics: A case study]. ESTEEM, 4(2), 91-103.

Hannula, M. S. (2002). Attitude towards mathematics: Emotions, expectations and values. Educational studies in Mathematics, 49(1), 25-46. https:/ / doi.org/10.1023/A:1016048823497

He, J., Sun, S., \& Fan, X. (2021). Validation of the 12-item short form of the eating disorder examination questionnaire in the Chinese context: Confirmatory factor analysis and Rasch analysis. Eating and Weight Disorders, 26(1), 201-209. https: / / doi.org/10.1007/s40519-019-00840-3

Hennig, C. (2010). Mathematical models and reality: a constructivist perspective. Foundations of Science, 15, 29-48. https:/ / doi.org/10.1007/S10699-009-9167-X

Hidayat, R., Qudratuddarsi, H., Mazlan, N. H., \& Zeki, M. Z. M. (2021). Evaluation of a test measuring mathematical modelling competency for Indonesian college students. Journal of Nusantara Studies, 6(2), 133-155. https://doi.org/10.24200/ jonus.vol6iss2pp133-155

Hidayat, R., Zamri, S. N. A. S, Zulnaidi, H., Abdullah, M. F. N. L., \& Adnan, M. (2021). The interrelationships between metacognition and modeling competency: the moderating role of the academic year. European Journal of Educational Research, 10(4), 1853-1866. https:// doi.org/10.12973/eu-jer.10.4.1853

Hidayat, R., Zamri, S. N. A. S., \& Zulnaidi, H. (2018). Exploratory and confirmatory factor analysis of achievement goals for Indonesian students in mathematics education programmes. EURASIA Journal of Mathematics, Science and Technology
Education, 14(12), em1648. https://doi.org/ 10.29333 / ejmste/ 99173

Hidayat, R., Zulnaidi, H., \& Syed Zamri, S. N. A. (2018). Roles of metacognition and achievement goals in mathematical modeling competency: A structural equation modeling analysis. PloS One, 13(11), $\mathrm{e} 0206211$.

https:/ / doi.org/10.1371/journal.pone.0206211

Hooper, D., Coughlan, J., \& Mullen, M. (2008). Structural equation modelling: Guidelines for determining model fit. The Electronic Journal of Business Research Methods, 6, 53-60.

Hunt J. (2007). Communicating big themes in applied mathematics. In P. Haines, W. Galbraith, W. Blum, \& S. Khan (Eds.), Mathematical modeling (ICTMA12): Education, engineering and economics (pp. 2-24). Horwood Publishing. https://doi.org/10.1533/ 9780857099419.1.1

Iseppi, L., Rizzo, M., Gori, E., Nassivera, F., Bassi, I., \& Scuderi, A. (2021). Rasch model for assessing propensity to entomophagy. Sustainability, 13(8), 4346. https:/ / doi.org/10.3390/su13084346

Kasmin, F., Othman, Z., \& Syed Ahmad, S. S. (2019). Improving students' perception towards learning mathematics: impact of teaching application of mathematics. EDUCATUM Journal of Science, Mathematics and Technology, 6(1), 29-34. https:// doi.org/10.37134/ejsmt.vol6.1.4.2019

Khairani, A. Z. (2017). Assessing urban and rural teachers' competencies in STEM integrated education in Malaysia. In MATEC Web of Conferences (vol. 87, p. 04004). EDP Sciences. https:/ / doi.org/10.1051/matecconf/20178704004

Kline, R. B. (2005). Principles and practice of structural equation modeling. The Guilford Press.

Kohen, Z., \& Orenstein, D. (2021). Mathematical modeling of tech-related real-world problems for secondary school-level mathematics. Educational Studies in Mathematics, 107(1), 71-91. https://doi.org/10.1007/s10649-020-10020-1

Leavy, A., Hourigan, M., \& Carroll, C. (2017). Exploring the impact of reform mathematics on entry-level pre-service primary teachers attitudes towards mathematics. International Journal of Science and Mathematics Education, 15(3), 509-526. https:// doi.org/10.1007/s10763-015-9699-1

Lee, J., \& Paek, I. (2014). In search of the optimal number of response categories in a rating scale. Journal of Psychoeducational Assessment, 32(7), 663-673. https:/ / doi.org/10.1177/0734282914522200

Leong, K. E., \& Tan, J. Y. (2020). Exploring secondary students' modelling competencies. The Mathematics Enthusiast, 17(1), 85-107. 
Leung, A. (2019). Exploring STEM pedagogy in the mathematics classroom: A tool-based experiment lesson on estimation. International Journal of Science and Mathematics Education, 17(7), 1339-1358. https:/ / doi.org/10.1007/s10763-018-9924-9

Leung, S. O. (2011). A comparison of psychometric properties and normality in 4-, 5-, 6-, and 11-point likert scales. Journal of Social Service Research, 37(4), 412-421.

https:/ / doi.org/10.1080/01488376.2011.580697

Lozano, L. M., García-Cueto, E., \& Muñiz, J. (2008). Effect of the number of response categories on the reliability and validity of rating scales. Methodology, $4(2), \quad 73-79 . \quad$ https://doi.org/10.1027/16142241.4.2.73

Maa $\beta$, K. (2006). What are modeling competencies? Zentralblatt FüR Didaktik Der Mathematik, 38(2), 113142. https:// doi.org/10.1007/BF02655885

Mardia, K. V. (1974). Applications of some measures of multivariate skewness and kurtosis in testing normality and robustness studies. Sankhyā: The Indian Journal of Statistics, Series B, 36(2), 115-128.

McLeod, D. (1992). Research on affect in mathematics education: a reconceptualization. In D. Grows (Ed.), Handbook of research on mathematics teaching and learning (pp. 575-596). McMillan.

Obrad, C. (2020). Constraints and consequences of online teaching. Sustainability, 12(17), 6982. https:/ / doi.org/10.3390/su12176982

Osbourne, J. W. (2015). What is rotating in exploratory factor analysis? Practical Assessment, Research, and Evaluation, 20(2), 1-7.

Pollak, H. O. (2011). What is mathematical modeling? Journal of Mathematics Education at Teachers College, 2(1), 64.

Purnami, W., Sumintono, B., \& Wahyu, Y. (2021). Investigation of person ability and item fit instruments of eco critical thinking skills in basic science concept materials for elementary preservice teachers. Jurnal Pendidikan IPA Indonesia, 10(1), 127-137. https:/ / doi.org/10.15294/jpii.v10i1. 25239

Raykov, T. (2004). Behavioral scale reliability and measurement invariance evaluation using latent variable modeling. Behavior Therapy, 35, 299-331. https:/ / doi.org/10.1037/cou0000192

Rouquette, A., Hardouin, J. B., Vanhaesebrouck, A., Sébille, V., \& Coste, J. (2019). Differential item functioning (DIF) in composite health measurement scale: Recommendations for characterizing DIF with meaningful consequences within the Rasch model framework. PLOS ONE, 14(4), 1-16. https://doi.org/10.1371/journal.pone. 0215073
Sabudin, G., \& Halim, L. (2020). Kajian sistematik: pendekatan pengajaran dan impak khazanah pengetahuan dalam pembelajaran sains. Jurnal Pendidikan Sains Dan Matematik Malaysia, 10(1), 2138.

https://doi.org/10.37134/jpsmm.vol10.1.4.2020

Sahin, S., Dogan, M. F., Cavus Erdem, Z., Gurbuz, R., \& Temurtas, A. (2019). Prospective teachers' criteria for evaluating mathematical modeling problems. International Journal of Research in Education and Science, 5(2), 730-743.

Scoulas, J. M., Aksu Dunya, B., \& De Groote, S. L. (2021). Validating students' library experience survey using rasch model. Library and Information Science Research, 43(1), 101071. https://doi.org/10.1016/ j.lisr.2021.101071

Shahbari, J. A., \& Peled, I. (2015). Resolving cognitive conflict in a realistic situation with modeling characteristics: Coping with a changing reference in fractions. International Journal of Science and Mathematics Education, 13(4), 891-907. https: / / doi.org/10.1007/s10763-014-9509-1

Singer, F. M., \& Moscovici, H. (2008). Teaching and learning cycles in a constructivist approach to instruction. Teaching and Teacher Education, 24(6), 1613-1634. https:// doi.org/10.1016/j.tate.2007.12.002

Stillman, G., Kaiser, G., Blum, W., \& Brown, J. (Eds, 2013). Teaching mathematical modelling: connecting to research and practice. Springer. https:/ / doi.org/10.1007/978-94-007-6540-5

Suryadi, B., Hayat, B., Dwirifqi, M., \& Putra, K. (2021). The Indonesian version of the life orientation testrevised (LOT-R): psychometric properties based on the Rasch model The Indonesian version of the life orientation test-revised (LOT-R): Psychometric properties based on the Rasch model. Cogent Psychology, 8(1), 1869375. https:/ / doi.org/10.1080/ 23311908.2020.1869375

Tajudin, A., \& Abdullah, N. (2018). Kesediaan guru sains sekolah rendah terhadap pelaksanaan pembelajaran abad ke-21 [The readiness of primary school science teachers towards the implementation of 21st century learning]. Jurnal Pendidikan Sains Dan Matematik Malaysia, 8(1), 8297. https:/ / doi.org/10.37134/jpsmm.vol8.1.7.2018

Tennant, A., \& Conaghan, P. G. (2007). The Rasch measurement model in rheumatology: What is it and why use it? when should it be applied, and what should one look for in a Rasch paper? Arthritis $\mathcal{E}$ Rheumatism, 57(8), 1358-1362. https:/ / doi.org/10.1002/art.23108

Tiilikainen, M., Karjalainen, J., Toom, A., Lepola, J., \& Husu, J. (2019). The complex zone of constructivist teaching: a multi-case exploration in primary 
classrooms. Research Papers in Education, 34(1), 3860.

https:/ / doi.org/10.1080/02671522.2017.1402080

Van Zile-tamsen, C. (2019). Using Rasch analysis to inform rating scale development. Research in Higher Education, 58(8), 922-933. https:/ / doi.org/10.1007/ s11162-017-9448-0

Wang, J. \& Wang, X. (2019). Structural equation modeling: applications using mplus (2nd ed.). John Wiley \& Sons Ltd. https:/ / doi.org/10.1002/9781119422730
Yong, W., Hutagalung, F. D., Hidayat, R., \& Zulnaidi, H. (2020). A comparison study of Chinese and Indonesia EFL teachers' well-being. Psychology and Education, 57(4), 233-238.

Zainudin Awang, Lim, S., \& Nur Fairuza Syahira. (2018). Pendekatan mudah SEM (Structural Equation Modelling). MPWS.

\section{http://www.ejmste.com}

